\title{
The impact of the Coronavirus (COVID-19) pandemic on mental health- A short review article
}

\author{
Alia Amiri 1, Abhishek S. Lachyan 2, Somya Gautam 3, Kumud Kaushik ${ }^{3}$, and Aishwarya Potnis 4, *, Prachi \\ Gangurde ${ }^{5}$ and Manal Moeej Ibji 6 \\ ${ }^{1}$ Department of Public Health, School of Health Sciences, Noida International University, Delhi NCR. \\ 2 Department of Social and Preventive Medicine, Faculty of Medicine, University Malaya, Kuala Lumpur, Malaysia. \\ ${ }^{3}$ School of Nursing and Health Sciences, Noida International University, Delhi NCR. \\ ${ }^{4}$ Occupational Therapy School and Center, Seth G.S. Medical College, King Edward Memorial Hospital, Mumbai-400012, \\ Maharashtra, India. \\ ${ }^{5}$ Baroda Heart Institute \& Research Centre, Vadodara, Gujarat, India. \\ ${ }^{6}$ Parkar Hospitals \& Research Institute, Ratnagiri, Maharashtra, India.
}

International Journal of Biological and Pharmaceutical Sciences Archive, 2021, 02(01), 176-178

Publication history: Received on 11 August; revised on 24 September 2021; accepted on 26 September 2021

Article DOI: https://doi.org/10.53771/ijbpsa.2021.2.1.0086

\begin{abstract}
The people have been informed about the physical repercussions of SARS-CoV-2 infection across the world, as well as how to avoid exposure to the coronavirus and the treatment of COVID-19 symptoms if they arise. The consequences of the pandemic on one's mental health, on the other hand, have not been well investigated and are yet unknown. Because all efforts have been concentrated on studying the epidemiology, clinical characteristics, transmission patterns, and management of the COVID-19 pandemic, little concern has been raised about the consequences on one's mental health or methods to avoid stigmatization. Various psychological issues and significant mental health effects, such as stress, worry, sadness, frustration, and uncertainty, developed gradually throughout the COVID-19 pandemic. The goal of this study was to conduct a thorough assessment of the available research on the effects of COVID-19 infection on mental health in the general population.
\end{abstract}

Keywords: Coronavirus (COVID-19); Pandemic; Mental health; Prevalence; Community; Lockdown

\section{Overview}

The Coronavirus Disease 2019 (COVID-19) pandemic has posed significant mental health risks throughout the world as a major virus pandemic in the twenty-first century. While patients and healthcare professionals receive psychological assistance, the mental health of the general population also deserves consideration. During the COVID-19 pandemic, we looked at the general public's mental health and the variables that influence it. When compared to the prevalence before the pandemic, there is a greater prevalence of signs of poor mental consequences among the general population. A pandemic is more than simply a medical emergency; it impacts people and society, causing chaos, worry, stress, stigma, and xenophobia. Individual conduct as a unit of society or a community has a significant impact on the environment. The intensity, degree of flow, and aftereffects of a pandemic are all factors to consider. Because of the rapid human-tohuman transmission of SARS-CoV-2, regional lockdowns were imposed to prevent the disease from spreading further [1]. Isolation, social alienation, and the shutdown of educational institutions, jobs, and entertainment venues forced individuals to stay at home in order to break the transmission cycle. The restrictions, on the other hand, have definitely had a negative impact on people's social and mental health. As more individuals are compelled to remain at home in

\footnotetext{
* Corresponding author: Aishwarya Potnis
}

Baroda Heart Institute \& Research Centre, Vadodara, Gujarat, India.

Copyright (@) 2021 Author(s) retain the copyright of this article. This article is published under the terms of the Creative Commons Attribution Liscense 4.0. 
self-isolation in order to avoid the spread of the disease at a societal level, governments must take the appropriate steps to give mental health assistance as recommended by specialists. Author said in his editorial that health systems throughout the globe are gathering solely to combat the COVID-19 pandemic, which has the potential to have a significant impact on the treatment of other diseases, including mental health, which is often exacerbated during pandemics. An individual's psychological condition as it relates to community health differs from person to person and is influenced by his history, career and social status. Self-isolation and quarantine are likely to have a detrimental influence on one's mental health [2]. Separation from loved ones, loss of independence, boredom, and uncertainty can lead to a decline in an individual's mental health, according to an analysis published in The Lancet. Individual and societal-level initiatives are necessary to overcome this. Both children and adults are experiencing a range of emotions as a result of the present world scenario. Knowing the COVID-19 outbreak's consequences on different groups' mental health is just as essential as understanding its clinical characteristics, transmission patterns, and management. Spending time with family members, especially youngsters and the elderly, participating in various healthy workouts and sports activities, sticking to a schedule/routine, and avoiding conventional and social media can all assist to overcome mental health difficulties [3]. In the current scenario, public awareness efforts concentrating on maintaining mental health are critical [4]. To mitigate the psychological and emotional effects of the COVID-19 pandemic, specific community-level preventative methods such as (i) establishing effective communication and (ii) providing sufficient psychological assistance should be implemented. Health education should be improved via the use of internet platforms, social dread connected to COVID-19 should be handled appropriately, and stigma and discrimination should be acknowledged as important issues capable of reinforcing feelings of insecurity in a time of social crisis [5].

\section{Conclusion}

The current study provides a snapshot of the acute phase impact of COVID-19 on the mental health of the community. The findings are suggesting markedly elevated rates of depression and anxiety, even among individuals with no current diagnosis. Overall, the findings suggest that interventions to counteract the social, financial and role disruptions induced by COVID-19, particularly among people with existing health conditions, are likely to have the greatest impact on community mental health and wellbeing.

This study provides an awareness regarding the impact on mental health and also promotes the techniques to prevent the same.

\section{Compliance with ethical standards}

\section{Acknowledgments}

I would like to extend my greatest gratitude to my supervisors for their guidance and inspiration in completing this research. I would like to extend a special thanks to all my friends their endless support and assistance in the development of this research.

Last but not the least, this acknowledgement is incomplete if I fail in my duty to thank all my study subjects who have whole-heartedly participated in the study and have made the study complete.

\section{Disclosure of conflict of interest}

None declared.

\section{Funding}

No funding sources.

\section{References}

[1] Xiong J, Lipsitz O, Nasri F, Lui LM, Gill H, Phan L, Chen-Li D, Iacobucci M, Ho R, Majeed A, McIntyre RS. Impact of COVID-19 pandemic on mental health in the general population: A systematic review. Journal of affective disorders. 2020 Aug 8.Javed B, Sarwer A, Soto EB, Mashwani Z-R. The coronavirus (COVID-19) pandemic's impact on mental health. Int J Health Plann Mgmt. 2020; 1-4. https://doi.org/10.1002/hpm.3008

[2] Abhishek Lachyan, Vineet Kumar, Samiksha Ingale, Karan Gade,"Analyzing The Impact Of Covid-19 Vaccine Infodemic On Social Media: A Study Of Human Behaviour In State Of Uttar Pradesh, India", Ijrar - International 
Journal of Research and Analytical Reviews (IJRAR), E-ISSN 2348-1269, P- ISSN 2349-5138, Volume.6, Issue 2, Page No pp.852-863, May 2019.

[3] Javed B, Sarwer A, Soto EB, Mashwani ZU. The coronavirus (COVID-19) pandemic's impact on mental health. The International journal of health planning and management. 2020 Sep;35(5):993-6.

[4] Lachyan AS, Fui WM, Zaki RA, Banerjee B, Furqan S, Adhikari H, John R, Potnis A. COVID-19 vaccines: A method based on social pharmacology.

[5] Serafini G, Parmigiani B, Amerio A, Aguglia A, Sher L, Amore M. The psychological impact of COVID-19 on the mental health in the general population. QJM: An International Journal of Medicine. 2020 Aug 1; 113(8):531-7. 